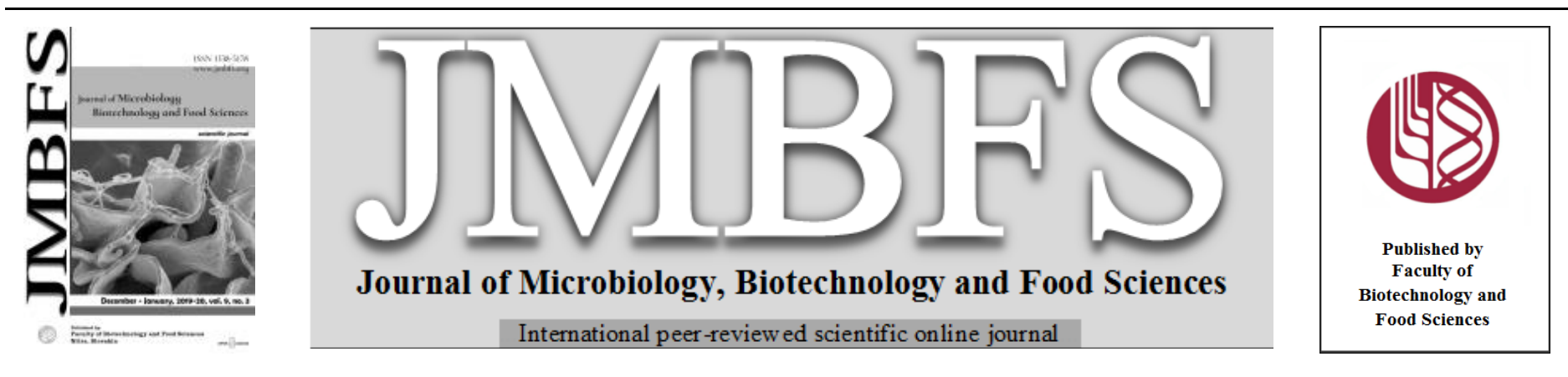

\title{
OPTIMIZATION AND COMPARISON OF DIFFERENT TECHNIQUES FOR EXTRACTION OF FLAVONOIDS OF BULGARIAN MAVRUD GRAPE BY-PRODUCTS
}

\author{
Vanya Dimcheva*I, Maria Karsheva ${ }^{1}$ \\ Address(es): Ing. Vanya Dimcheva, MSc \\ ${ }^{1}$ Dept.of Chemical Engineering, University of Chemical Technology and Metallurgy, 8, St. Kliment Ohridski Blvd., 1756, Sofia, Bulgaria.
}

*Corresponding author: vdimcheva@uctm.edu

doi: 10.15414/jmbfs.2019/20.9.3.510-515

\section{ARTICLE INFO}

Received 28. 1. 2019

Revised 12. 5. 2019

Accepted 13. 5. 2019

Published 1. 12. 2019

Regular article OPEN $\partial_{\text {Access }}$

\begin{abstract}
In recent years, the interest in antioxidants in grape by-products has increased significantly as scientific research for the extraction and quantification of these compounds. In the present investigation was optimized the antioxidant yield of the grape pomace and seeds discharged as waste from the Bulgarian Mavrud winery, near to Trakiets village. There is a lack of information about extraction optimization and utilization of the selected grape by-products. The aim of the paper was studying the influence of some process parameters: effect of the degreasing pre-treatment of the material, effect of the extraction method and the extraction time on the yield of total flavonoid and anthocyanin contents and Trolox equivalent antioxidant capacity (TEAC). For this propose the extraction kinetics were obtained by using conventional and non-conventional extraction methods - magnetic stirring and ultrasound-assisted extraction (UAE) and using of degreased and non-degreased plant material. Degreasing was done by conventional Soxhlet extraction with $\mathrm{n}$ hexane for an hour. All analyses were done using ultraviolet-visible (UV-vis) spectrophotometry. The results obtained show that the applied ultrasound power after the degreasing pre-treatment promoted optimal anthocyanin and flavonoid recovery for 180 minutes extraction time of both - grape pomace and seeds. The TEAC is not affected by applying UAE and degreasing pre-treatment technique. The optimization of the extraction conditions is important because it could alter an economic impact on the extraction evaluation of the Mavrud grape by-products. The grape pomace and seeds from Bulgarian Mavrud wine-making can be used to obtain secondary derivatives with high-added antioxidant value.
\end{abstract}

Keywords: Bulgarian Mavrud, grape pomace, grape seeds, flavonoids, anthocyanins, antioxidant capacity, ultrasound-assisted extraction

\section{INTRODUCTION}

Wine consumption has increased over the years and, along with that, the concomitant increase in grape pomace production became an important subject of research. Solid waste produced after winemaking might account for over $30 \%$ (w/w) of the grapes used. Grape pomace is the main solid organic waste from winery industries; resulting from the pressing and/or fermentation processes it is generated in large amounts in many parts of the world (Abarghuei et al., 2010; Christ et al., 2013)

The main components of grape pomace are seeds and skin. Studies have shown the potential of phenolics and antioxidant fibers recovery from the skin (Brenes et al., 2016), as well as oil recovery from the seeds (Fiori et al., 2014). However, there is still a long way to go until all these residues gain a real recovery pathway, thus making the winemaking process a more sustainable activity.

Wine production generates solid wastes as grape marcs and liquids called "wine by-products" (Martinez-carrasco et al., 2005). These by-products are also of interest to the cosmetics industry. Indeed, the wine contains many phenolic compounds that possess antioxidant properties. These compounds play an essential role in the mechanism of skin rejuvenation. Thus, in recent years, the interest in antioxidants has increased significantly as scientific research for the extraction and quantification of these compounds.

Grape pomace consists of the skin, stems, and seeds that remain after grapes processing in the wine industry, where large amounts of bagasse are generated. However, grape pomace may become a product with a potential economic return since it is the source of bioactive compounds (phenolic compounds, fatty acids, pectins, etc.) that may be used in the manufacturing of food products. Furthermore, grape pomace may be used in ethanol production and in the recovery of organic acids, while the grape seeds are a source of several types of oil (Krishnaswamy et al., 2012). Specifically, grape skin is a source of anthocyanins, natural pigments with antioxidant properties and may be used to recover hydrocolloids and phenolic compounds (Rodríguez et al., 2010). Generally, grape skin has antimutagenic activities (Pedreschi et al., 2006).
Grape seeds are known to be rich in procyanidins (Tounsi et al., 2009) which have been reported for cardioprotective effects (Bagchi et al., 2003), cataract prevention (Yamakoshi et al., 2002), antihyperglycemic effects (Pinent $\boldsymbol{e t}$ al., 2004), anti-inflammatory effects (Terra et al., 2007) as well as anticancer efficacy (Veluri et al., 2006).

Recovery of the antioxidant components in the grape pomace and seeds is commonly performed in the literature and a lot of data is available. Moreover, the results are difficult to be compared even because the different extraction procedures are used, or the different grape varieties by-products are extracted. There is a lack in the literature concerning the systematic approaches to optimize the extraction process aiming to maximize the extraction yield and antioxidant power of the Bulgarian grape by-products. The extraction optimization of the Bulgarian Mavrud grape pomace and seeds is important because both low-cost wine-making wastes can be used to obtain secondary derivatives with high antioxidant value.

\section{MATERIAL AND METHODS}

\section{Plant materials}

In the present study were used grape pomace and grape seeds recovered as a residue from a vinification process in the Mavrud winery „Lozev wine Ltd.“, Bulgaria. The grape for wine production was collected from 2016 harvest at the winery in the „Trakiets” village.

\section{Chemicals}

Ethanol (96 \%) was supplied by Valerus (Sofia, Bulgaria). Methanol (HPLC grade), sodium nitrite $\left(\mathrm{NaNO}_{2}\right)$, sodium acetate $\left(\mathrm{CH}_{3} \mathrm{COONa}\right)$, potassium chloride (KCL), n-hexane $(\geq 99 \%)$ and aluminum chloride hexahydrate $\left(\mathrm{AlCl}_{3} \times\right.$ $6 \mathrm{H}_{2} \mathrm{O}$ ) was supplied by Merck (Sofia, Bulgaria). Folin-Ciocalteau reagent, 2,2diphenyl-1-picrylhydrazyl (DPPH), rutin hydrate, quercetin hydrate $(\geq 95 \%),(-)$ - 
catechin hydrate ( $\geq 96 \%$ ), sodium hydroxide, malvidin 3-glucoside (97 $\%)$, cyanidin 3-glucoside (97 \%) and Trolox (6-hydroxy-2,5,7,8 tetramethylchroman-2-carboxylic acid) $(97 \%)$ were supplied by Sigma Aldrich (Sofia, Bulgaria). Ammonia iron alum was supplied by Scharlau (Sofia, Bulgaria). Deionized water was from an "Elix70C Gulfstream" water deionizer supplied by Merck (Germany).

\section{Sample preparation and extraction procedure}

The grape pomace and the grape seeds were kept frozen in the freezer $\left(-18{ }^{\circ} \mathrm{C}\right)$ for six months. Before examinations, the frozen samples were left at room temperature for $24 \mathrm{~h}$ after that were dried using an air conventional drier at $57^{\circ} \mathrm{C}$ for 4 hours.

It is well established that the phenolic compounds are heat sensitive substances, therefore temperatures lower than $60{ }^{\circ} \mathrm{C}$ are considered suitable for the pretreatment of grape pomace in order to keep its bioactive compounds (Bocco $e t$ al., 1998).

The water content of the pomace and seeds was measured. The values found were $10.50 \%$ for the grape pomace and $8.24 \%$ - for the seeds. For the experimental runs were used grape pomace (skins: seeds, 90:10) and grape seeds The grape seeds were chopped with a particles fraction size from $0.5-1.0 \mathrm{~mm}$ and the grape pomace was left whole. The stems accompanying usual the pomace was separate and non-used. All experiments on extraction kinetics were carried out at constant parameters: RT (room temperature approx. $25^{\circ} \mathrm{C}$ ), $50 \%$ ethanol in water solution, and $0.1 \mathrm{~g} . \mathrm{L}^{-1}$ solid to the solvent ratio $(1 \mathrm{~g}$ grape pomace or seeds to $10 \mathrm{ml}$ solvent). Part of the pomace and the seeds were extracted with $\mathrm{n}$ hexane through conventional Soxhlet apparatus. Afterthought was performed extraction kinetics applying constant ultrasound power of $280 \mathrm{~W}$ and frequency of $25 \mathrm{kHz}$ on an ultrasound bath (AU-32, ARGOLAB, Italy) and by applying conventional extraction at 1411 RCF (relative centrifugal force) through magnetic stirrer (MS-H-Pro+, Dragon Laboratory Instruments, China). At certain previously determined times $(5,10,15,20,30,50,80,120,180,220)$ samples of the extracts were taken, filtered and analyzed immediately for total flavonoid content (TFC), total anthocyanin content (TAC) and TEAC. For the UAE all samples in each single extraction run were placed in the center of the ultrasound bath with the dept of the 3 centimeters and each batch of samples to be sonicated was kept the same position. Besides this, all samples of each experiment were sonicated simultaneously in the ultrasonic device.

Soxhlet extraction was conducted by the following manner: plant material (30.0 g) - homogenized pomace or seeds was placed in Whatman No. 1 (Watchmen, GE Healthcare, UK) filter paper and transferred to a reflux type Soxhlet extractor. The Soxhlet extractions were carried out for an hour using n-hexane as a solvent $(300 \mathrm{~mL})$ and heated under reflux. The long pre-treatment could lead to degradation of flavonoids and anthocyanins during refluxing. That is why a minimum time for degreasing was chosen. Thereafter the extracted plan materials were air dried and kept in a tightly closed dark glass tube. Al extraction kinetics were performed in duplicate and the results were expressed as mean value \pm standard deviation $(\mathrm{SD})$

\section{Total flavonoid content}

The formation of a flavonoid- aluminum complex was employed to determine the flavonoid content (Patel et al., 2010). An aliquot of $1 \mathrm{~mL}$ previously diluted extract $(0.3 \mathrm{~mL}$ of the extract was added to a $10 \mathrm{~mL}$ volumetric flask containing deionized water), $4 \mathrm{~mL}$ of deionized water, and $0.3 \mathrm{~mL}$ of $5 \% \mathrm{NaNO}_{2}$ was dropped into a $10 \mathrm{~mL}$ volumetric flask. After 5 minutes, $0.3 \mathrm{~mL} \mathrm{AlCl}(10 \%)$ and $2 \mathrm{~mL}$ of $1 \mathrm{M} \mathrm{NaOH}$ were added. Finally, a volume of $10 \mathrm{~mL}$ was adjusted with deionized water.

A standard curve of quercetin was drowned ((0.5-5.0) g.. $\mathrm{L}^{-1}, \mathrm{y}=0.2175 . \mathrm{x}$ $\left.\mathrm{R}^{2}=0.9936\right)$ and the results were expressed as quercetin equivalents per gram dry weight $(\mathrm{mg} \mathrm{QE} / \mathrm{g} \mathrm{dw}$ ) and calculated by the following formula:

$$
\mathrm{TFC}=\mathrm{C} \times \mathrm{V} \times \mathrm{F} / \mathrm{M}
$$

where TFC is the total flavonoids content, $\mathrm{mg} \mathrm{QE} / \mathrm{g} \mathrm{dw}$; $\mathrm{C}$ is the concentration of quercetin, g. $\mathrm{L}^{-1} ; \mathrm{V}$ is the volume of the used solvent, $\mathrm{L} ; \mathrm{F}$ is the dilution coefficient of the sample; $M$ is the mass of the sample, $g$.

\section{Total anthocyanin content}

This method makes possible to determine the total anthocyanins' content and is based on the change in the structure of this compound between $\mathrm{pH} 1.0$ and 4.5 . Depending on the $\mathrm{pH}$ of the solution in which they are present, these compounds are either in flavylium form colored at $\mathrm{pH} 1.0$ or in colorless hemiacetal form at $\mathrm{pH}$ 4.5. The absorbance was measured spectrophotometrically at $510 \mathrm{~nm}$ and 700 $\mathrm{nm}$ respectively. So, the difference in absorbance is proportional to the concentration of anthocyanins and was calculated using the following equation:

$\mathrm{Abs}=(\mathrm{A} 510-\mathrm{A} 700) \mathrm{pH} 1.0-(\mathrm{A} 510-\mathrm{A} 700) \mathrm{pH} 4.5$ where A510 - absorbance of the sample measured at $510 \mathrm{~nm}$ with buffers $\mathrm{pH} 1.0$ and $\mathrm{pH} 4.5$, respectively; A700 - absorbance of the sample measured at $700 \mathrm{~nm}$ with buffers $\mathrm{pH} 1.0$ and $\mathrm{pH} 4.5$, respectively (Lee et al., 2005).

The determination of total anthocyanins was carried out as follows. For the preparation of the buffer solution with $\mathrm{pH} 1.0$, an aliquot of $1.86 \mathrm{~g}$ of KCL was dissolved in $980 \mathrm{~mL}$ deionized water. Then, for the preparation of the buffer solution with $\mathrm{pH} 4.5$, an aliquot of $53.43 \mathrm{~g} \mathrm{CH}_{3} \mathrm{COONa}$ was dissolved in $960 \mathrm{~mL}$ deionized water. After that, an aliquot of $0.6 \mathrm{~mL}$ of the extract was introduced into a microcuvette with $2.4 \mathrm{~mL}$ buffer solution. The absorbance was measured at $510 \mathrm{~nm}$ and $700 \mathrm{~nm}$ respectively. The TAC was calculated using the following equation:

$$
\mathrm{TAC}=(\mathrm{A} \times \mathrm{MW} \times \mathrm{DF} \times \mathrm{V} \times 1000) /(\mathrm{E} \times \mathrm{L} \times \mathrm{M})
$$

where: TAC - the equivalent of cyanidin-3-glucoside (CGE) or malvidin-3glucoside (MGE), mg. $\mathrm{L}^{-1}$, MW molecule mass of cyanidin-3-glucoside (449.2 g. $\left.\mathrm{mol}^{-1}\right)$ or molecule mass of malvidin glucoside $\left(493 \mathrm{~g} \cdot \mathrm{mol}^{-1}\right)$. DF - dilution factor; $\mathrm{E}$ - the molar absorbance of cyanidin-3-glucoside $\left(\left(26900(\mathrm{~L} . \mathrm{cm}) \cdot \mathrm{mol}^{-1}\right)\right)$ or the molar absorbance of malvidin glucoside $\left(\left(20200(\mathrm{~L} \cdot \mathrm{cm}) \cdot \mathrm{mol}^{-1}\right)\right), \mathrm{M}-$ the mass of the sample, $\mathrm{g}$; $\mathrm{L}-$ the cell path length $(1 \mathrm{~cm})$.

The results were expressed as $\mathrm{mg}$ cyanidin and respectively malvidin glucoside equivalent per 100 grams dry weight (mg CGE, MGE/100 dw).

\section{TEAC}

The chemical 2,2-diphenyl-1-picrylhydrazyl, known as DPPH, is one of the first free radicals used to study the antioxidant activity of phenolic compounds. DPPH solutions show high absorption at $517 \mathrm{~nm}$ due to the dark blue color. The decrease in the blue color is measurable spectrophotometrically which allows estimating the effectiveness of the antioxidant's presence (Loizzo et al., 2010).

The determination of antioxidant capacity was carried out as follows:

Preparation of the DPPH solution: an aliquot of $0.0040 \mathrm{~g}$ of DPPH, was dissolved in $100 \mathrm{~mL}$ of methanol.

Sample preparations: An aliquot of $1 \mathrm{~mL}$ of the extracts (previously diluted 10 times) were added to $4 \mathrm{~mL}$ of DPPH solution.

The samples were stored in the dark for $30 \mathrm{~min}$. The absorbance was measured at $517 \mathrm{~nm}$. Free radical scavenging ability or inhibition capacity of the tested samples was calculated using the formula (Yen et al., 1994):

$$
\mathrm{IC}=(\mathrm{Ao}-\mathrm{Aa}) / \mathrm{Ao} \times 100
$$

where: IC - inhibition capacity, \%; Ao - the average value of absorbance blank AA - the average value of absorbance sample;

The TEAC assay is often used to measure the antioxidant capacity of foods and nutritional supplements. The Trolox (6-hydroxy-2,5,7,8-tetramethylchroman-2 carboxylic acid) is an antioxidant vitamin E derivative [20]. The results obtained were performed using the Trolox concentration linearity range of $2.5-175$ $\mu$ mol. $\mathrm{L}^{-1}$. The obtained equation of rights was $\mathrm{y}=1.332 . \mathrm{x}+0.5634$, where the, $\mathrm{y}^{\mathrm{c}}$ is the concentration of the Trolox solution (plotted on the ordinate), and the „ $\mathrm{x}$ " is the absorbance (plotted on the abscise). The TEAC was calculated using the formula:

$$
\text { TEAC }=\text { IC sample }-1.332 / 0.5634
$$

where: TEAC - Trolox equivalent antioxidant capacity, $\mu$ mol TEAC. $\mathrm{L}^{-1}$; IC inhibition capacity of sample, \%; 1.332 - the slope of the Trolox calibration curve; 0.5634 - the intercept from the Trolox calibration curve.

The data obtained were expressed in $\mu \mathrm{mol}$ Trolox equivalent per gram dry weight ( $\mu \mathrm{mol} \mathrm{TEAC/g} \mathrm{dw)} \mathrm{after} \mathrm{using} \mathrm{the} \mathrm{mass} \mathrm{of} \mathrm{the} \mathrm{samples.}$

\section{Water content}

The water content of the selected samples was evaluated gravimetrically following the corresponding European pharmacopeia's method. About $2.0 \mathrm{~g}$ of the grape pomace or seeds were dried at $105^{\circ} \mathrm{C}$ in an oven to a constant mass ( Loss on drying 2.8.17., Eur.Ph.).

\section{RESULTS AND DISCUSSION}

There are no results on the literature about extraction optimization of the Mavrud by-products discharged from the winery in the region of Trakiets village except the study of Dimcheva et al., (2018). The polyphenol composition of grape pomace depends on many factors, not only the environmental factors in which the grapes are matured but also on the type of solvent used, the analytical technique, extraction manner, the extraction time as well as the presence of interfering substances (Dimcheva et al., 2018). The extraction efficiency may be significantly influenced by operating parameters, not only by changing the extraction time and solvent composition but by applying an ultrasound power and 
temperature (Gironi et al., 2011; Ma et al., 2009). The mechanical effects of ultrasound induce a greater penetration of solvent into cellular materials and improve mass transfer. Ultrasound extraction can also disrupt biological cell walls, facilitating the discharge of contents (Mason et al., 1996).

In the present investigation all kinetical experiments were done with $50 \%$ ethanol in water solution because was earlier found as optimal with the same plant material by Dimcheva et al., (2018). Likewise, $50 \%$ of ethanol was chosen as the most adequate conditions for phenolic compounds recovery of the grape skins reported by Caldas et al., (2018). Methanol seems to be the most effective, followed by ethanol than water according to Pinelo et al., (2005). Nevertheless, for food application, ethanol and water are preferred because of hygiene, low cost, and health compatibility (Moure $\boldsymbol{e t}$ al., 2001). Ethanol concentration has been reported to affect the phenolic compounds extraction since it diminishes the boiling point and influences the polarity of the mixed solvent (Wijngaard $\boldsymbol{e t}$ al. 2009).

Recently, along with the variables in the optimization of the plant extraction, namely solvent/sample ratio, type of solvent, time and temperature, a method of extraction and pre-treatment of the sample such as degreasing is commonly used.

In Table 1 provided below are presented total monomeric anthocyanin kinetic study obtained by UAE of previously degreased and non-degreased separately grape pomace and grape seeds.

Table 1 Total monomeric anthocyanins calculated as cyanidin and malvidin glucoside equivalents per $100 \mathrm{~g} / \mathrm{dw}$ obtained by UAE before and after degreasing with $n$-hexane of grape pomace and grape seeds

\begin{tabular}{|c|c|c|c|c|c|c|c|c|}
\hline & \multicolumn{2}{|c|}{ Without degreasing } & \multicolumn{2}{|c|}{ After degreasing } & \multicolumn{2}{|c|}{ Without degreasing } & \multicolumn{2}{|c|}{ After degreasing } \\
\hline $\begin{array}{c}\text { Time, } \\
\text { min }\end{array}$ & $\mathbf{C G E} \pm \mathbf{S D}^{*}$ & MGE $\pm \mathbf{S D}^{*}$ & $\mathrm{CGE} \pm \mathrm{SD}^{*}$ & $\mathbf{M G E} \pm \mathbf{S D}^{*}$ & $\mathbf{C G E} \pm \mathrm{SD}^{*}$ & $\mathbf{M G E} \pm \mathbf{S D}^{*}$ & $\mathrm{CGE} \pm \mathrm{SD}^{*}$ & MGE $\pm \mathbf{S D}^{*}$ \\
\hline 5 & $1.00 \pm 1.25$ & $1.46 \pm 1.78$ & $1.30 \pm 1.09$ & $1.90 \pm 0.98$ & $16.83 \pm 1.65$ & $24.60 \pm 1.12$ & $39.24 \pm 2.10$ & $57.35 \pm 0.56$ \\
\hline 10 & $2.00 \pm 0.87$ & $2.93 \pm 1.78$ & $1.60 \pm 1.29$ & $2.34 \pm 1.34$ & $17.63 \pm 2.07$ & $25.77 \pm 2.35$ & $42.42 \pm 0.67$ & $61.99 \pm 2.00$ \\
\hline 15 & $2.40 \pm 1.28$ & $3.51 \pm 0, .78$ & $1.70 \pm 2.45$ & $2.49 \pm 1.23$ & $26.18 \pm 1.78$ & $38.27 \pm 0.56$ & $74.31 \pm 1.89$ & $108.61 \pm 2.01$ \\
\hline 20 & $2.50 \pm 2.00$ & $3.66 \pm 1.89$ & $2.00 \pm 0.67$ & $2.93 \pm 1.76$ & $34.47 \pm 0.98$ & $50.37 \pm 1.89$ & $120.40 \pm 1.09$ & $175.97 \pm 1.56$ \\
\hline 30 & $2.91 \pm 1.76$ & $4.25 \pm 1.96$ & $2.10 \pm 1.55$ & $3.08 \pm 1.33$ & $32.86 \pm 0.87$ & $48.03 \pm 1.89$ & $151.96 \pm 1.76$ & $222.09 \pm 0.78$ \\
\hline 50 & $3.21 \pm 0.76$ & $4,69 \pm 2.15$ & $3.11 \pm 1.78$ & $4,54 \pm 0.68$ & $53.57 \pm 1.76$ & $78.29 \pm 1.23$ & $166.99 \pm 1.13$ & $244.06 \pm 0.67$ \\
\hline 80 & $3.41 \pm 1.68$ & $4.98 \pm 1.23$ & $4.81 \pm 1.12$ & $7.03 \pm 1.26$ & $74.28 \pm 2.15$ & $108.56 \pm 2.08$ & $168.83 \pm 1.98$ & $246.74 \pm 1.60$ \\
\hline 120 & $4,91 \pm 0.90$ & $7.18 \pm 1.65$ & $8.00 \pm 0.56$ & $11.69 \pm 1.34$ & $95.92 \pm 1.23$ & $140,19 \pm 1.89$ & $176.17 \pm 1.90$ & $257.48 \pm 1.76$ \\
\hline 180 & $5.51 \pm 1.26$ & $8.15 \pm 1.66$ & $9.22 \pm 0.79$ & $13.47 \pm 0.45$ & $101.66 \pm 0.79$ & $148.58 \pm 1.68$ & $204.34 \pm 1.87$ & $298.66 \pm 1.26$ \\
\hline 220 & $5.61 \pm 1.56$ & $8.24 \pm 2.34$ & $9.23 \pm 1.25$ & $13.62 \pm 1.57$ & $102.00 \pm 1.25$ & $149.08 \pm 1.80$ & $205.00 \pm 1.12$ & $299.62 \pm 1.96$ \\
\hline
\end{tabular}

Legend: CGE - Cyanidin glucoside equivalent, MGE - Malvidin glucoside equivalent, SD - standard deviation,

*Extractions were performed in duplicate and the results are expressed as the mean \pm standard deviation (SD).

Based on the kinetic results it can be concluded that the optimal yield of the desired components is achieved after 180 minutes. Or, it is evident, that UAE after degreasing with n-hexane increases the yield of the anthocyanins almost twice for the grape pomace and for the grape seeds. For the grape seeds, the anthocyanins reached before decreasing from 8.15 to $13.47 \mathrm{mg}$ MGE/100 g dw, respectively, after it. For the grape pomace, the MGE anthocyanins are increased from 148.58 to value of $298.66 \mathrm{mg}$ MGE/100 $\mathrm{g} \mathrm{dw}$ which is almost 2 times larger after an hour degreasing in comparison with of the case without degreasing. The non-polar nature of the chosen solvent n-hexane is interacting with the non-polar compounds which are content permanently in all plant matrices. Therefore, is achieving a higher concentration of the polar constituents in the grape byproducts such as polyphenols and anthocyanins. The best results obtained in the kinetics shown above are from 2 to 4 times less than total anthocyanins in the best red wines (Brenes et al., 2016) which demonstrates the possibility to use the by-products.

Lapornik et al., (2005) was proposed a potential alternative for an industria solid-liquid extraction process of antioxidant compounds from grape pomace. The incubation temperature was increased up to $93{ }^{\circ} \mathrm{C}$, the time of the process was reduced to 93 minutes and was used $66 \%$ ethanol/water as a solvent mixture to be obtained an optimal value of $70.3 \mathrm{mg}$ CGE/100g dw total monomeric anthocyanins. The received result by Lapornik $\boldsymbol{e t}$ al., (2005) is almost like our value obtained from non-degreased pomace at $80^{\text {th }}$ minute $-74.28 \mathrm{mg} \mathrm{CGE} / 100 \mathrm{~g}$ $\mathrm{dw}$ but is 2.4 lower than obtained from degreased grape pomace - $168.83 \mathrm{mg}$ CGE/100g dw (Table 1).

In Table 2 and Table 3 was carried out the total flavonoid's kinetics obtained by $\mathrm{UAE}$ of the degreased and non-degreased grape by-products.

Table 2 Total flavonoid content calculated as quercetin, rutin and (-) catechin equivalents per g/dw, obtained by UAE before and after degreasing with $n$-hexane of grape seeds

\begin{tabular}{|c|c|c|c|c|c|c|}
\hline \multirow[b]{2}{*}{ Time, min } & \multicolumn{3}{|c|}{ Without degreasing } & \multicolumn{3}{|c|}{ After degreasing } \\
\hline & $\mathbf{Q E} \pm \mathbf{S D}^{*}$ & $\mathbf{R E} \pm \mathbf{S D}^{*}$ & $\mathbf{C E} \pm \mathbf{S D}^{*}$ & $\mathbf{Q E} \pm \mathbf{S D}^{*}$ & $\mathbf{R E} \pm \mathbf{S D}^{*}$ & $\mathrm{CE} \pm \mathrm{SD}^{*}$ \\
\hline 5 & $5.52 \pm 1.11$ & $2.51 \pm 1.04$ & $0.75 \pm 0.95$ & $7.76 \pm 0.56$ & $3.53 \pm 1.78$ & $1.05 \pm 1.13$ \\
\hline 10 & $5.92 \pm 1.10$ & $2.69 \pm 1.07$ & $0.80 \pm 1.26$ & $12.80 \pm 1.36$ & $5.82 \pm 0.67$ & $1.73 \pm 0.79$ \\
\hline 15 & $6.48 \pm 1.29$ & $2.95 \pm 1.45$ & $0.88 \pm 0.87$ & $15.52 \pm 0.78$ & $7.05 \pm 1.58$ & $2.10 \pm 1.89$ \\
\hline 20 & $6.80 \pm 1.01$ & $3.09 \pm 1.40$ & $0.92 \pm 0.55$ & $16.64 \pm 0.45$ & $7.56 \pm 0.12$ & $2.25 \pm 0.98$ \\
\hline 30 & $7.84 \pm 1.48$ & $3.56 \pm 1.22$ & $1.06 \pm 0.15$ & $21.28 \pm 1.49$ & $9.67 \pm 1.78$ & $2.88 \pm 1.21$ \\
\hline 50 & $7.28 \pm 1.31$ & $3.31 \pm 1.45$ & $0.98 \pm 1.20$ & $26.00 \pm 0.12$ & $11.82 \pm 0.29$ & $3.51 \pm 0.35$ \\
\hline 80 & $9.76 \pm 0.29$ & $4.44 \pm 0.75$ & $1.32 \pm 0.85$ & $35.84 \pm 0.76$ & $16.29 \pm 0.57$ & $4.84 \pm 1.29$ \\
\hline 120 & $13.12 \pm 1.14$ & $5.96 \pm 1.29$ & $1.77 \pm 0.45$ & $44.00 \pm 1.08$ & $20.00 \pm 0.96$ & $5.95 \pm 0.78$ \\
\hline 180 & $20.40 \pm 0.78$ & $9.27 \pm 1.57$ & $2.76 \pm 1.85$ & $53.20 \pm 0.84$ & $24.18 \pm 0.57$ & $7.19 \pm 0.69$ \\
\hline 220 & $20.50 \pm 1.14$ & $9.42 \pm 1.45$ & $2.92 \pm 1.28$ & $53.50 \pm 0.48$ & $24.25 \pm 1.27$ & $7.27 \pm 1.89$ \\
\hline & \multicolumn{6}{|c|}{ Grape seeds } \\
\hline
\end{tabular}

Legend: QE - quercetin equivalent, RE - rutin equivalent, CE - (-) catechin equivalent SD - standard deviation

*Extractions were performed in duplicate and the results are expressed as the mean \pm standard deviation (SD).

Degreased grape seeds extracted by UAE show 2.3 times better yield than nondegreased ones (Table 2).

For the grape pomace, the obtained results are much better than the grape seeds the flavonoid yield in the degreased grape pomace is increased 3.5 times more than non-degreased ones as shown in Table 3. For the total flavonoids' kinetics, the optimal extraction time was found as a $180^{\text {th }}$ minutes, like the anthocyanin kinetic study.
In Table 4 is shown the kinetic study by TAC of the same degreased and nondegreased by-products extracted by conventional extraction method - magnetic stirring. 
Table 3 Total flavonoid content calculated as quercetin, rutin and (-) catechin equivalents per $\mathrm{g} / \mathrm{dw}$, obtained by UAE before and after degreasing with $\mathrm{n}$-hexane of grape pomace

\begin{tabular}{|c|c|c|c|c|c|c|}
\hline \multirow[b]{2}{*}{ Time, $\min$} & \multicolumn{2}{|c|}{ Without degreasing } & \multicolumn{3}{|c|}{ After degreasing } & \multirow[b]{2}{*}{$\mathrm{CE} \pm \mathrm{SD}^{*}$} \\
\hline & $\mathbf{Q E} \pm \mathbf{S D}^{*}$ & $\mathbf{R E} \pm \mathbf{S D}^{*}$ & $\mathbf{C E} \pm \mathbf{S D}^{*}$ & $\mathbf{Q E} \pm \mathbf{S D}^{*}$ & $\mathbf{R E} \pm \mathbf{S D}^{*}$ & \\
\hline 5 & $5.36 \pm 1.25$ & $2.44 \pm 1.29$ & $0.72 \pm 0.80$ & $9.28 \pm 0.59$ & $4.22 \pm 1.44$ & $1.25 \pm 1.31$ \\
\hline 10 & $7.12 \pm 1.05$ & $3.24 \pm 1.25$ & $0.96 \pm 0.79$ & $11.52 \pm 1.36$ & $5.24 \pm 0.89$ & $1.56 \pm 0.65$ \\
\hline 15 & $7.84 \pm 1.18$ & $3.56 \pm 1.12$ & $1.06 \pm 0.95$ & $12.96 \pm 0.78$ & $7.89 \pm 1.18$ & $1.75 \pm 1.49$ \\
\hline 20 & $8.56 \pm 1.58$ & $3.89 \pm 1.47$ & $1.16 \pm 0.98$ & $16.00 \pm 0.63$ & $7.27 \pm 0.79$ & $2.16 \pm 1.58$ \\
\hline 30 & $13.28 \pm 0.36$ & $6.04 \pm 1.05$ & $1.79 \pm 1.25$ & $17.44 \pm 1.11$ & $7.93 \pm 1.13$ & $2.36 \pm 1.58$ \\
\hline 50 & $15.76 \pm 1.69$ & $7.16 \pm 1.58$ & $2.13 \pm 1.06$ & $24.40 \pm 1.44$ & $11.09 \pm 1.08$ & $3.30 \pm 1.43$ \\
\hline 80 & $23.44 \pm 1.45$ & $10.65 \pm 1.36$ & $3.17 \pm 0.36$ & $64.00 \pm 0.11$ & $29.09 \pm 1.69$ & $8.65 \pm 1.76$ \\
\hline 120 & $28.64 \pm 1.28$ & $13.02 \pm 1.45$ & $3.87 \pm 0.89$ & $88.00 \pm 1.55$ & $40.00 \pm 0.36$ & $11.89 \pm 1.06$ \\
\hline 180 & $30.40 \pm 1.30$ & $13.82 \pm 1.11$ & $4.11 \pm 0.36$ & $108.00 \pm 0.63$ & $49.09 \pm 1.00$ & $14.59 \pm 0.47$ \\
\hline 220 & $30.80 \pm 1.14$ & $14.02 \pm 0.25$ & $4.27 \pm 0.98$ & $108.05 \pm 1.82$ & $49.51 \pm 1.47$ & $15.00 \pm 0.89$ \\
\hline
\end{tabular}

Grape pomace
Legend: QE - quercetin equivalent, RE - rutin equivalent, $\mathbf{C E}$ - (-) catechin equivalent SD - standard deviation
*Extractions were performed in duplicate and the results are expressed as the mean \pm standard deviation (SD).

Table 4 Total monomeric anthocyanins calculated as cyanidin and malvidin glucoside equivalents per $100 \mathrm{~g} / \mathrm{dw}$, obtained through magnetic stirrer before and after degreasing with n-hexane of grape pomace and grape seeds

\begin{tabular}{|c|c|c|c|c|c|c|c|c|}
\hline & \multicolumn{2}{|c|}{ Without degreasing } & \multicolumn{2}{|c|}{ After degreasing } & \multicolumn{2}{|c|}{ Without degreasing } & \multicolumn{2}{|c|}{ After degreasing } \\
\hline $\begin{array}{c}\text { Time, } \\
\text { min }\end{array}$ & $\mathbf{C G E} \pm \mathrm{SD}^{*}$ & MGE $\pm \mathbf{S D}^{*}$ & $\mathbf{C G E} \pm \mathrm{SD}^{*}$ & MGE $\pm \mathbf{S D}^{*}$ & $\mathbf{C G E} \pm \mathbf{S D}^{*}$ & $\mathrm{MGE} \pm \mathbf{S D}^{*}$ & $\mathbf{C G E} \pm \mathbf{S D}^{*}$ & $\mathbf{M G E} \pm \mathbf{S D}^{*}$ \\
\hline 5 & $0.20 \pm 0.58$ & $0.29 \pm 1.89$ & $1.10 \pm 1.18$ & $1.61 \pm 1.28$ & $38.24 \pm 1.80$ & $55.89 \pm 1.48$ & $32.06 \pm 1.08$ & $46.86 \pm 1.45$ \\
\hline 10 & $0.30 \pm 1.08$ & $0 . .44 \pm 1.13$ & $1.60 \pm 1.12$ & $2.35 \pm 1.12$ & $39.08 \pm 1.13$ & $57.11 \pm 2.11$ & $42.48 \pm 1.89$ & $62.09 \pm 1.25$ \\
\hline 15 & $1.50 \pm 2.25$ & $2.20 \pm 1.08$ & $1.70 \pm 1.29$ & $2.49 \pm 1.45$ & $53.94 \pm 1.00$ & $78.83 \pm 1.46$ & $55.84 \pm 2.28$ & $81.61 \pm 1.12$ \\
\hline 20 & $1.90 \pm 1.25$ & $2.79 \pm 0.25$ & $2.71 \pm 1.15$ & $3.96 \pm 1.08$ & $55.11 \pm 0.56$ & $80.54 \pm 1.08$ & $59.31 \pm 1.55$ & $86.69 \pm 1.78$ \\
\hline 30 & $2.61 \pm 1.48$ & $3.81 \pm 1.25$ & $2.91 \pm 0.69$ & $4.25 \pm 1.95$ & $58.78 \pm 1.89$ & $85.91 \pm 1.55$ & $69.87 \pm 1.45$ & $102.11 \pm 1.15$ \\
\hline 50 & $3.31 \pm 1.13$ & $4.84 \pm 1.13$ & $3.11 \pm 0.58$ & $4.55 \pm 1.59$ & $69.13 \pm 0.25$ & $101.04 \pm 1.59$ & $74.41 \pm 1.12$ & $108.75 \pm 1.13$ \\
\hline 80 & $3.61 \pm 1.26$ & $5.28 \pm 1.12$ & $3.61 \pm 1.16$ & $5.28 \pm 1.13$ & $69.30 \pm 1.25$ & $101.28 \pm 2.28$ & $98.46 \pm 1.09$ & $143.90 \pm 1.07$ \\
\hline 120 & $4.21 \pm 1.45$ & $6.16 \pm 1.09$ & $4.81 \pm 1.14$ & $7.04 \pm 1.09$ & $71.30 \pm 1.09$ & $104.21 \pm 1.19$ & $112.00 \pm 1.19$ & $163.69 \pm 1.89$ \\
\hline 180 & $4.71 \pm 1.89$ & $6.90 \pm 1.55$ & $5.01 \pm 1.09$ & $7.34 \pm 1.48$ & $84.83 \pm 0.58$ & $123.98 \pm 1.25$ & $126.78 \pm 1.25$ & $185.29 \pm 1.45$ \\
\hline 220 & $4.81 \pm 1.95$ & $7.01 \pm 1.89$ & $5.11 \pm 1.12$ & $7.35 \pm 1.08$ & $84.93 \pm 1.18$ & $124.10 \pm 0.58$ & $127.10 \pm 1.18$ & $185.98 \pm 1.55$ \\
\hline & \multicolumn{4}{|c|}{ Grape seeds } & \multicolumn{4}{|c|}{ Grape pomace } \\
\hline
\end{tabular}

Legend: CGE - Cyanidin glucoside equivalent, MGE - Malvidin glucoside equivalent, SD - standard deviation

*Extractions were performed in duplicate and the results are expressed as the mean \pm standard deviation (SD).

It can be seen that the values of the monomeric anthocyanins are lower than previous TAC' kinetic. Nevertheless, the UAE kinetics the optimal extraction time when applying magnetic stirring is again about a $180^{\text {th }}$ minute. It can be concluded that the UAE does not decrease the extraction time of the grape pomace and seeds at the expense of higher yields for the same time. In Table 4 again are compared the kinetic before and after Soxhlet extraction but the increase of anthocyanin yield under magnetic stirring is negligible unlike when using the UAE. The MGE anthocyanins increasing only from 6.90 to $7.34 \mathrm{mg}$ MGE/100g dw for the seeds and from 123.98 to $185.29 \mathrm{mg} \mathrm{MGE} / 100 \mathrm{~g} \mathrm{dw}$ for the pomace. From comparing the kinetics conducted through magnetic stirring and UAE, can be concluded that the UAE, almost doubles the anthocyanins yield from 185.98 to $298.66 \mathrm{mg} \mathrm{MGE} / 100 \mathrm{~g} \mathrm{dw}$ when is extracted grape pomace and from 7.35 to $13.47 \mathrm{mg} \mathrm{MGE} / 100 \mathrm{~g}$ dw when the grape seeds are extracted. This can be explained with the hard nature of the grape seeds and ungrounded pomace that release more useful components when is applied ultrasound power and mass transfer is improved.

In Table 5 and Table 6 are shown the kinetic studies performed through magnetic stirrer by total flavonoids of the degreased and non-degreased grape seeds and pomace. Likewise, the kinetics by total anthocyanins extracted from the same plant material through magnetic stirrer the optimal extraction time is again about the $180^{\text {th }}$ minute. The values of the total flavonoids in the presented kinetics are lower than flavonoids obtained by UAE. The QE flavonoids before and after degreasing are increased from 12.56 to $16.16 \mathrm{mg} \mathrm{QE} / \mathrm{g} \mathrm{dw}$ for the seeds and from 25.04 to $36.24 \mathrm{mg} \mathrm{QE} / \mathrm{g} \mathrm{dw}$ for the pomace. Can be concluded that UAE increases almost twice the flavonoids' yields of grape by-products but do not decrease the extraction time. There are bioactive substances which need more time for discharging, nevertheless applying ultrasonic power has a positive effect on the yields of anthocyanins and flavonoids in the Mavrud grape by-products.

Table 5 Total flavonoid content calculated as quercetin, rutin and (-) catechin equivalents per g/dw, obtained by magnetic stirring before and after degreasing with n-hexane of grape seeds

\begin{tabular}{|c|c|c|c|c|c|c|}
\hline \multirow[b]{2}{*}{ Time, min } & \multicolumn{3}{|c|}{ Without degreasing } & \multicolumn{3}{|c|}{ After degreasing } \\
\hline & $\mathbf{Q E} \pm \mathbf{S D}^{*}$ & $\mathbf{R E} \pm \mathbf{S D}^{*}$ & $\mathbf{C E} \pm \mathbf{S D}^{*}$ & $\mathbf{Q E} \pm \mathbf{S D}^{*}$ & $\mathbf{R E} \pm \mathbf{S D}^{*}$ & $\mathrm{CE} \pm \mathrm{SD}^{*}$ \\
\hline 5 & $7.20 \pm 1.18$ & $3.27 \pm 1.27$ & $0.97 \pm 1.14$ & $7.92 \pm 1.49$ & $3.60 \pm 1.18$ & $1.07 \pm 1.45$ \\
\hline 10 & $7.20 \pm 1.44$ & $3.27 \pm 1.77$ & $0.97 \pm 1.78$ & $8.16 \pm 1.18$ & $3.71 \pm 1.67$ & $1.10 \pm 0.58$ \\
\hline 15 & $8.08 \pm 0.58$ & $3.67 \pm 1.10$ & $1.09 \pm 1.75$ & $9.76 \pm 1.98$ & $4.44 \pm 2.18$ & $1.32 \pm 1.56$ \\
\hline 20 & $8.96 \pm 1.46$ & $4.07 \pm 0.23$ & $1.21 \pm 1.18$ & $9.76 \pm 0.58$ & $4.44 \pm 1.49$ & $1.32 \pm 1.55$ \\
\hline 30 & $9.12 \pm 1.17$ & $4.15 \pm 1.14$ & $1.23 \pm 1.48$ & $10.00 \pm 1.67$ & $4.55 \pm 1.77$ & $1.35 \pm 1.11$ \\
\hline 50 & $9.76 \pm 1.12$ & $4.44 \pm 1.11$ & $1.32 \pm 1.88$ & $11.20 \pm 1.18$ & $5.09 \pm 1.47$ & $1.51 \pm 1.78$ \\
\hline 80 & $11.84 \pm 0.58$ & $5.38 \pm 1.51$ & $1.60 \pm 1.18$ & $13.12 \pm 1.15$ & $5.96 \pm 0.58$ & $1.77 \pm 1.16$ \\
\hline 120 & $12.00 \pm 0.18$ & $5.45 \pm 1.58$ & $1.62 \pm 2.28$ & $14.88 \pm 1.13$ & $6.76 \pm 1.47$ & $2.01 \pm 1.25$ \\
\hline 180 & $12.56 \pm 1.89$ & $5.71 \pm 1.77$ & $1.70 \pm 0.58$ & $16.16 \pm 1.19$ & $7.35 \pm 1.45$ & $2.18 \pm 1.68$ \\
\hline 220 & $12.68 \pm 1.07$ & $5.96 \pm 1.48$ & $1.77 \pm 1.18$ & $16.96 \pm 1.47$ & $7.71 \pm 1.58$ & $2.29 \pm 1.78$ \\
\hline
\end{tabular}

\section{Grape seeds}

Legend: QE - quercetin equivalent, RE - rutin equivalent, CE - (-) catechin equivalent SD - standard deviation $*$ Extractions were performed in duplicate and the results are expressed as the mean \pm standard deviation (SD). 
Table 6 Total flavonoid content calculated as quercetin, rutin and (-) catechin equivalents per g/dw, obtained by magnetic stirring before and after degreasing with $n$-hexane of grape pomace

\begin{tabular}{cc|c|c|c|c|c|}
\hline & \multicolumn{3}{c}{ Without degreasing } & \multicolumn{3}{c}{ After degreasing } \\
\hline Time, min & QE \pm SD $^{*}$ & RE $\pm \mathbf{S D}^{*}$ & $\mathbf{C E} \pm \mathbf{S D}^{*}$ & $\mathbf{Q E} \pm \mathbf{S D}^{*}$ & $\mathbf{R E} \pm \mathbf{S D}$ & $\mathbf{C E}^{*} \mathbf{S D}^{*}$ \\
\hline 5 & $6.40 \pm 1.27$ & $2.91 \pm 1.36$ & $0.86 \pm 1.89$ & $6.96 \pm 1.23$ & $3.16 \pm 1.36$ & $0.94 \pm 1.63$ \\
10 & $7.04 \pm 1.65$ & $3.20 \pm 1.78$ & $0.95 \pm 1.27$ & $8.32 \pm 1.29$ & $3.78 \pm 1.66$ & $1.12 \pm 1.36$ \\
15 & $7.84 \pm 1.29$ & $3.56 \pm 1.27$ & $1.06 \pm 0.78$ & $10.64 \pm 1.22$ & $4.84 \pm 1.54$ & $1.44 \pm 1.23$ \\
20 & $8.80 \pm 1.66$ & $4.00 \pm 1.42$ & $1.19 \pm 1.48$ & $12.24 \pm 1.65$ & $5.56 \pm 1.16$ & $1.65 \pm 1.45$ \\
30 & $10.96 \pm 0.47$ & $4.98 \pm 1.05$ & $1.48 \pm 1.06$ & $14.48 \pm 1.54$ & $6.58 \pm 1.27$ & $1.96 \pm 1.78$ \\
50 & $14.56 \pm 1.27$ & $6.62 \pm 1.27$ & $1.97 \pm 0.36$ & $17.04 \pm 1.27$ & $7.75 \pm 1.27$ & $2.30 \pm 1.35$ \\
80 & $17.84 \pm 1.98$ & $8.11 \pm 1.24$ & $2.41 \pm 1.27$ & $19.44 \pm 0.79$ & $8.84 \pm 0.46$ & $2.63 \pm 1.49$ \\
120 & $21.28 \pm 1.45$ & $9.67 \pm 1.21$ & $2.88 \pm 1.69$ & $25.36 \pm 1.65$ & $11.53 \pm 1.32$ & $3.43 \pm 1.27$ \\
180 & $25.04 \pm 1.29$ & $11.38 \pm 1.78$ & $3.38 \pm 1.63$ & $36.24 \pm 1.78$ & $16.47 \pm 1.89$ & $4.90 \pm 1.43$ \\
220 & $25.08 \pm 1.32$ & $11.44 \pm 1.45$ & $3.48 \pm 1.98$ & $37.00 \pm 1.56$ & $16.57 \pm 2.27$ & $5.04 \pm 1.27$ \\
\hline
\end{tabular}

Grape pomace

Legend: QE - quercetin equivalent, RE - rutin equivalent, $\mathbf{C E}$ - (-) catechin equivalent, SD - standard deviation

*Extractions were performed in duplicate and the results are expressed as the mean \pm standard deviation (SD).

The TEAC kinetics of the grape seeds and pomace also was done. The antioxidant power of the degreased and non-degreased by-products extracted by UAE and by magnetic stirring are shown in Figure 7 and Figure 8, respectively. In comparison with other previous kinetics, where after degreasing of the samples, the flavonoids' and anthocyanins' yields are increasing almost from 2 to 3 times here in TEAC' kinetics there is no sensible increase. The UAE in comparison than stirring increase the TEAC with 1.5 times for the seeds. For the grape pomace, there is no difference when using the UAE and conventional extraction. The values obtained after degreasing are $30.52 \mu \mathrm{mol} \mathrm{TEAC} / \mathrm{g} \mathrm{dw}$ by $\mathrm{UAE}$ and $31.36 \mu \mathrm{mol} \mathrm{TEAC} / \mathrm{g}$ dw by stirring at the $180^{\text {th }}$ minute. In the presented kinetics the optimal extraction time again can be evaluated after $180^{\text {th }}$ minute.

Table 7 TEAC calculated as $\mu \mathrm{mol}$ TEAC/g dw, obtained by UAE before and after degreasing with $\mathrm{n}$ hexane of grape pomace and grape seeds

\begin{tabular}{cccccc}
\hline & Without degreasing & After degreasing & Without degreasing & After degreasing \\
\hline Time, min & TEAC \pm SD $^{*}$ & TEAC \pm SD $^{*}$ & TEAC \pm SD $^{*}$ & TEAC $^{*}$ SD $^{*}$ \\
\hline 5 & $12.38 \pm 1.78$ & $15.49 \pm 1.22$ & $11.46 \pm 1.21$ & $18.16 \pm 0.98$ \\
10 & $13.14 \pm 1.45$ & $21.13 \pm 1.79$ & $14.13 \pm 0.23$ & $21.58 \pm 1.80$ \\
15 & $13.33 \pm 1.49$ & $25.96 \pm 0.98$ & $15.88 \pm 1.28$ & $22.30 \pm 1.18$ \\
20 & $13.59 \pm 1.25$ & $25.54 \pm 1.09$ & $18.46 \pm 0.78$ & $23.37 \pm 1.75$ \\
30 & $14.39 \pm 1.14$ & $29.61 \pm 1.44$ & $21.20 \pm 1.96$ & $25.80 \pm 1.77$ \\
50 & $18.99 \pm 1.47$ & $30.90 \pm 1.24$ & $24.55 \pm 1.22$ & $30.33 \pm 1.58$ \\
80 & $22.42 \pm 1.09$ & $31.97 \pm 1.08$ & $27.78 \pm 1.65$ & $31.28 \pm 1.36$ \\
120 & $29.38 \pm 1.65$ & $32.16 \pm 1.05$ & $31.09 \pm 2.03$ & $31.36 \pm 1.90$ \\
180 & $32.16 \pm 1.40$ & $32.54 \pm 1.04$ & $31.36 \pm 1.71$ & $31.59 \pm 1.46$ \\
220 & $32.35 \pm 1.74$ & $32.73 \pm 1.25$ & $31.21 \pm 1.55$ & $32.88 \pm 1.61$ \\
\hline \multicolumn{5}{c}{ Grape seeds } & Grape pomace
\end{tabular}

Legend: TEAC - Trolox equivalent antioxidant capacity, SD - standard deviation

*Extractions were performed in duplicate and the results are expressed as the mean \pm standard deviation (SD).

Table 8 TEAC calculated as $\mu \mathrm{mol}$ TEAC/g dw, obtained by magnetic stirring before and after degreasing with $\mathrm{n}$-hexane of grape pomace and grape seeds

\begin{tabular}{c|cccc}
\hline & Without degreasing & After degreasing & Without degreasing & After degreasing \\
\hline Time, min & TEAC \pm SD $^{*}$ & TEAC $^{*}$ SD $^{*}$ & TEAC $^{*}$ SD $^{*}$ & TEAC $^{*}$ SD $^{*}$ \\
\hline 5 & $7.03 \pm 0.36$ & $10.24 \pm 1.67$ & $9.59 \pm 1.49$ & $11.03 \pm 1.45$ \\
10 & $11.23 \pm 1.40$ & $13.21 \pm 1.87$ & $10.70 \pm 1.51$ & $16.10 \pm 1.34$ \\
15 & $10.29 \pm 1.02$ & $14.61 \pm 1.44$ & $14.78 \pm 1.47$ & $19.27 \pm 1.40$ \\
20 & $14.41 \pm 1.34$ & $15.81 \pm 1.63$ & $15.64 \pm 2.00$ & $20.55 \pm 1.17$ \\
30 & $15.11 \pm 1.30$ & $17.17 \pm 0.98$ & $18.94 \pm 1.40$ & $22.89 \pm 1.13$ \\
50 & $17.99 \pm 1.46$ & $18.82 \pm 1.12$ & $25.70 \pm 1.46$ & $28.13 \pm 1.10$ \\
80 & $18.02 \pm 1.20$ & $20.34 \pm 1.42$ & $26.27 \pm 1.40$ & $29.28 \pm 1.47$ \\
120 & $18.16 \pm 1.41$ & $21.27 \pm 1.78$ & $28.66 \pm 1.36$ & $31.13 \pm 1.55$ \\
180 & $20.55 \pm 1.67$ & $22.89 \pm 2.02$ & $30.52 \pm 1.23$ & $31.63 \pm 1.78$ \\
220 & $20.59 \pm 1.05$ & $22.94 \pm 0.25$ & $31.01 \pm 1.56$ & $32.05 \pm 1.12$ \\
\hline
\end{tabular}

Legend: TEAC - Trolox equivalent antioxidant capacity, SD - standard deviation

*Extractions were performed in duplicate and the results are expressed as the mean \pm standard deviation (SD).

The UAE is alternative to conventional extraction methods because it may improve the mass transfer but not in all cases is the best extraction technique.

As concerns the influence of pre-treatment of the sample, it was shown in the literature that degreasing pre-treatment reduces total phenols yield, increasing only slightly the phenolic content of the extracts according to Spigno et al. (2007). However, in our study, degreasing increases only the yields of the total flavonoids and the anthocyanins without affecting of the TEAC.

\section{CONCLUSION}

There is increasing interest in the antioxidants of foods and nutraceuticals because of health benefits and the economical recovering the wastes containing bioactive molecules. In the present investigation, the results obtained show that the applied pre-treatment degreasing of the grape by-products and applied subsequent UAE for 180 minutes extraction time give optimal flavonoids' and anthocyanins' yields. The quantity of the total anthocyanin content after degreasing increase from 101.66 to $298.66 \mathrm{mg} \mathrm{MGE} / 100 \mathrm{~g} \mathrm{dw}$ and the quantity 
of the total flavonoids from 30.40 to $108.05 \mathrm{mg} \mathrm{QE} / \mathrm{g} \mathrm{dw}$ for the grape pomace For the grape seeds at the same extraction conditions the increasing after degreasing for the total anthocyanins is from 8.15 to $13.47 \mathrm{mg} \mathrm{MGE} / 100 \mathrm{~g} \mathrm{dw}$ and for the total flavonoids is from 20.40 to $53.20 \mathrm{mg} \mathrm{QE} / \mathrm{g} \mathrm{dw}$. From the present investigation can be concluded that the proper choice of extraction technique influents the extraction efficiency. In general, the degreasing with nhexane is a useful pre-treatment technique with a positive effect on the flavonoids' and anthocyanins' yields of the Mavrud pomace and seeds discharged from Bulgarian Mavrud winemaking.

The application of the UAE to the extraction of plant samples has increased in the last years. The UAE is an alternative to conventional extraction methods because it may improve the mass transfer and reducing the extraction time. However, in our investigation UAE do not reduce the extraction time but increases twice even three times the bioactive antioxidants yield (flavonoids and anthocyanins) in compression with the used conventional extraction. The TEAC of the grape byproducts is not affected by applying UAE and degreasing pre-treatment technique. Likewise, a mathematical model describing the mass transfer mechanism for both extraction methods should be developed in the future. A complete characterization of the extract's composition will help to understand the different nature of the Bulgarian Mavrud pomace and grape. Therefore, furthe extraction optimization is required for productive and substantial economic use of such valuable wastes to obtain high-value by-products, such as natural health remedies, food supplements, and novel food ingredients.

Acknowledgments: The authors acknowledge the financial support provided by the National Science Fund, Ministry of Education and Science of Bulgaria under Contract Grant ДН 07/12.

\section{REFERENCES}

ABARGHUEI, M. J., ROUZBEHAN, Y.ALIPOUR, D. 2010. The influence of the grape pomace on the ruminal parameters of sheep. Livestock Science, 132(13), 73-79. http://dx.doi.org/10.1016/j.livsci.2010.05.002

BAGCHI, D., SEN, C. K., RAY, S. D., DAS, D. K., BAGCHI, M., PREUSS, H. G.,VINSON, J. A. 2003. Molecular mechanisms of cardioprotection by a novel grape seed proanthocyanidin extract. Mutation Research/Fundamental and Molecular Mechanisms of Mutagenesis, 523-524, 87-97. http://dx.doi.org/10.1016/s0027-5107(02)00324-x

BOCCO, A., CUVELIER, M. E., RICHARD, H., BERSET, C. 1998. Antioxidant Activity and Phenolic Composition of Citrus Peel and Seed Extracts. Journal of Agricultural and Food Chemistry, 46(6), 2123-2129. http://dx.doi.org/10.1021/jf9709562

BRENES, A., VIVEROS, A., CHAMORRO, S., ARIJA, I. 2016. Use of polyphenol-rich grape by-products in monogastric nutrition. A review. Animal Feed Science and Technology, 211, 1-17. https://doi.org/10.1016/j.anifeedsci.2015.09.016

CAlDAS, T. W., MAZZA, K. E. L., TElES, A. S. C., MATTOS, G. N., BRÍGIDA, A. I. S., CONTE-JUNIOR, C. A., BORGUINI, R. G., GODOY, R. L. O., CABRAL, L. M. C., TONON, R. V. 2018. Phenolic compounds recovery from grape skin using conventional and non-conventional extraction methods. Industrial Crops and Products, 111, 86-91. http://dx.doi.org/10.1016/j.indcrop.2017.10.012

CHRIST, K. L., BURRITT, R. L. 2013. Critical environmental concerns in wine production: an integrative review. Journal of Cleaner Production, 53(15), 232 242. http://dx.doi.org/10.1016/j.jclepro.2013.04.007

DIMCHEVA, V., KARSHEVA, M., DIANKOV, S., HINKOV, I. 2018. Optimization of extraction of antioxidants from Bulgarian by-products. Journal of chemical technology and metallurgy, 53(4), 631-639.

Loss on drying 2.8.17., In European Pharmacopoeia 8th ed. Strasbourg: Council of Europe (COE), European Directorate for the Quality of Medicines (EDQM). FIORI, L., LAVELLI, V., DUBA, K. S., SRI HARSHA, P. S. C., MOHAMED, H. B., GUELLA, G. 2014. Supercritical $\mathrm{CO}_{2}$ extraction of oil from seeds of six grape cultivars: Modeling of mass transfer kinetics and evaluation of lipid profiles and tocol contents. The Journal of Supercritical Fluids, 94, 71-80. http://dx.doi.org/10.1016/j.supflu.2014.06.021

GIRONI, F., PIEMONTE, V. 2011. Temperature and solvent effects on polyphenol extraction process from chestnut tree wood. Chemical Engineering $\begin{array}{lllr}\text { Research and Design, } & 89(7), & 857-862 .\end{array}$ http://dx.doi.org/10.1016/j.cherd.2010.11.003

KRISHNASWAMY, K., ORSAT, V., GARIÉPY, Y., THANGAVEL, K. 2012. Optimization of Microwave-Assisted Extraction of Phenolic Antioxidants from Grape Seeds (Vitis vinifera). Food and Bioprocess Technology, 6(2), 441-455. http://dx.doi.org/10.1007/s11947-012-0800-2

LAPORNIK, B., PROŠEK, M., GOLC WONDRA, A. 2005. Comparison of extracts prepared from plant by-products using different solvents and extraction time. Journal of Food Engineering, 71(2), 214-222. http://dx.doi.org/10.1016/j.jfoodeng.2004.10.036

LEE, J., DURST, R. W., WROLSTAD, R. E. 2005. Determination of total monomeric anthocyanin pigment content of fruit juices, beverages, natural colorants, and wines by the $\mathrm{pH}$ differential method: collaborative study. Journal of AOAC international, 88(5), 1269-1279.

LOIZZO, M. R., TUNDIS, R., CHANDRIKA, U. G., ABEYSEKERA, A. M., MENICHINI, F., FREGA, N. G. 2010. Antioxidant and antibacterial activities on foodborne pathogens of Artocarpus heterophyllus Lam. (Moraceae) leaves extracts. Journal of food science, 75(5), M291-295. http://dx.doi.org/10.1111/j.1750-3841.2010.01614.x

MA, Y. Q., CHEN, J. C., LIU, D. H., YE, X. Q. 2009. Simultaneous extraction of phenolic compounds of citrus peel extracts: effect of ultrasound. Ultrasonics Sonochemistry, 16(1), 57-62. http://dx.doi.org/10.1016/j.ultsonch.2008.04.012 MARTINEZ-CARRASCO, L., BRUGAROLAS, M., MARTINEZ-POVEDA, A 2005. Quality wines and wines protected by a designation of origin: Identifying their consumption determinants. Journal of wine research, 16(3), 213-232. http://dx.doi.org/10.1080/09571260600556690

MASON, T. J., PANIWNYK, L., LORIMER, J. P. 1996. The uses of ultrasound in food technology. Ultrasonics Sonochemistry, 3(3), S253-S260. http://dx.doi.org/10.1016/s1350-4177(96)00034-x

MOURE, A., CRUZ, J. M., FRANCO, D., DOMÍNGUEZ, J. M., SINEIRO, J., DOMÍNGUEZ, H., JOSÉ NÚÑEZ, M. A., PARAJÓ, J. C. 2001. Natural antioxidants from residual sources. Food Chemistry, 72(2), 145-171. http://dx.doi.org/10.1016/s0308-8146(00)00223-5

PATEL, A. M., PATEL, B., PATEL, A. R., PATEL, N. M. 2010. Estimation of flavonoid, polyphenolic content and in vitro antioxidant capacity of leaves of Tephrosia purpurea Linn. (Leguminosae). International Journal of Pharma Sciences and Research, 1(1), 66-77.

PEDRESCHI, R., CISNEROS-ZEVALLOS, L. 2006. Antimutagenic and antioxidant properties of phenolic fractions from Andean purple corn (Zea mays L.). Journal of Agricultural and Food Chemistry, 54(13), 4557-4567. http://dx.doi.org/10.1021/jf0531050

PINELO, M., RUBILAR, M., JEREZ, M., SINEIRO, J., NUNEZ, M. J. 2005. Effect of solvent, temperature, and solvent-to-solid ratio on the total phenolic content and antiradical activity of extracts from different components of grape pomace. Journal of Agricultural and Food Chemistry, 53(6), 2111-2117. http://dx.doi.org/10.1021/jf0488110

PINENT, M., BLAY, M., BLADE, M. C., SALVADO, M. J., AROLA, L., ARDEVOL, A. 2004. Grape seed-derived procyanidins have an antihyperglycemic effect in streptozotocin-induced diabetic rats and insulinomimetic activity in insulin-sensitive cell lines. Endocrinology, 145(11), 4985-4990. http://dx.doi.org/10.1210/en.2004-0764

RODRÍGUEZ, L. A., TORO, M. E., VAZQUEZ, F., CORREA-DANERI, M. L. GOUIRIC, S. C., VALLEJO, M. D. 2010. Bioethanol production from grape and sugar beet pomaces by solid-state fermentation. International Journal of Hydrogen Energy, 35(11)

5914-5917. http://dx.doi.org/10.1016/j.ijhydene.2009.12.112

SPIGNO, G., DE FAVERI, D. M. 2007. Antioxidants from grape stalks and marc: influence of extraction procedure on yield, purity and antioxidant power of the extracts. Journal of Food Engineering, 78(3), 793-801. https://doi.org/10.1016/j.jfoodeng.2005.11.020

TERRA, X., VAllS, J., VITRAC, X., MERRILlON, J. M., AROLA, L., ARDEVOL, A., BLADE, C., FERNANDEZ-LARREA, J., PUJADAS, G., SALVADO, J., et al. 2007. Grape-seed procyanidins act as antiinflammatory agents in endotoxin-stimulated RAW 264.7 macrophages by inhibiting NFkB signaling pathway. Journal of Agricultural and Food Chemistry, 55(11), 43574365. http://dx.doi.org/10.1021/jf0633185

TOUNSI, M. S., OUERGHEMMI, I., WANNES, W. A., KSOURI, R., ZEMNI, H., MARZOUK, B., KCHOUK, M. E. 2009. Valorization of three varieties of grape. Industrial Crops and Products, 30(2), 292-296. http://dx.doi.org/10.1016/j.indcrop.2009.05.007

VELURI, R., SINGH, R. P., LIU, Z., THOMPSON, J. A., AGARWAL, R. AGARWAL, C. 2006. Fractionation of grape seed extract and identification of gallic acid as one of the major active constituents causing growth inhibition and apoptotic death of DU145 human prostate carcinoma cells. Carcinogenesis, 27(7), 1445-1453. http://dx.doi.org/10.1093/carcin/bgi347

WIJNGAARD, H., BRUNTON, N. 2009. The optimization of extraction of antioxidants from apple pomace by pressurized liquids. Journal of Agricultural and Food Chemistry, 57(22), 10625-10631. http://dx.doi.org/10.1021/jf902498y YAMAKOSHI, J., SAITO, M., KATAOKA, S., TOKUTAKE, S. 2002. Procyanidin-Rich Extract from Grape Seeds Prevents Cataract Formation in Hereditary Cataractous (ICR/f) Rats. Journal of Agricultural and Food Chemistry, 50(17), 4983-4988. http://dx.doi.org/10.1021/jf0201632

YEN, G. C., DUH, P. D. 1994. Scavenging Effect of Methanolic Extracts of Peanut Hulls on Free-Radical and Active-Oxygen Species. Journal of Agricultural and Food Chemistry, 42(3), 629-632. http://dx.doi.org/10.1021/jf00039a005 